\title{
R. Shane Tubbs, J. Iwanaga, M. Loukas, R. J. Oskouian (Eds): Clinical anatomy of the ligaments of the craniocervical junction
}

\author{
Cambridge Scholars Publishing: Newcastle upon Tyne: 2019, pp302, BW and colored figures, \\ hard cover. \$87.65. ISBN (10) 1-5275-2203-3
}

\section{Concezio Di Rocco ${ }^{1}$}

Published online: 2 August 2019

(C) Springer-Verlag GmbH Germany, part of Springer Nature 2019

The ligamentous structures that connect and stabilize the occiput to $\mathrm{C} 1$ and $\mathrm{C} 2$ vertebrae and assure the particular functional mobility of the craniocervical junction have never received such special attention as that provided by Dr. Tubbs and his group in this "special" book. Indeed, the book offers a detailed embryological, anatomical, and functional description of each ligament together with the general bony anatomy. It also illustrates the pathological changes that the single ligament can undergo following traumatic injury or inflammatory pathological processes. In the last years, the congenital and acquired anomalies of the craniocervical region have been the subject of increasing attention by the neurosurgeon due to the diffusion of modern diagnostic tools, the availability of sophisticated technical instruments, and the introduction of new surgical techniques. The book considered here responds to this interest offering a theoretical basis for a better understanding of the functional anatomy of a very complex region. Besides the high scientific quality, the book presents several significant advances as compared to the traditional atlases: it does not forget to give due tribute to the contributions offered by previous anatomists not limited to quotations of their works but reporting excerpts of the books of extraordinary anatomists published at the end of the nineteenth century, namely, Henry Morris and Jean Léo Testut. Also the important study in comparative anatomy of the occipital-atlanto-axial ligament system published by the French anatomist Paul Hecker in 1922 has been translated and included in the book. The iconographic apparatus is simple, appealing, and easy to understand. The anatomical figures are associated with numerous explanatory drawings and the small format makes the book easy to consult when discussing clinical cases or planning surgical procedures.

In summary, the book is a precious contribution to the understanding of all aspects of the craniocervical junction which should not only be part of the armamentarium of the neurosurgeon involved in clinical practice but also of the students and neurosurgeons in training who want to be acquainted with one of the more complex functional regions of the body.

Publisher's note Springer Nature remains neutral with regard to jurisdictional claims in published maps and institutional affiliations.
Concezio Di Rocco

dirocco@ini-hannover.de

1 Pediatric Neurosurgery, International Neuroscience Institute, Rudolf Pichlmayir Strasse 4, 30625 Hannover, Germany 